\title{
NEW ELECTROMAGNETIC DYNAMOMETER: MEASURING THE SURFACE TENSION OF LIQUIDS
}

\author{
A. Benabdellah ${ }^{1}$, Z. Abbassi ${ }^{2}$, A. Nakheli ${ }^{3}$ \\ ${ }^{I}$ Moulay Ismail University, F.S, Laboratory LASMAR, Meknes, Morocco \\ ${ }^{2}$ Moulay Ismail University, F.S, Laboratory LASMAR, Meknes, Morocco \\ ${ }^{3}$ Moulay Ismail University, EST BP 3103 Toulal, Meknes, Morocco
}

\begin{abstract}
We realized an electromagnetic force sensor for measuring the surface tension of liquids by Wilhelmy plate method. The accuracy of the sensor is $\Delta m=0.3 \mathrm{mg}$ and referring to the force is $\Delta F=3 \mu N$. the surface tension of water-ethanol systems was obtained by the accuracy of $\Delta \sigma=0.06$ dynes $/ \mathrm{cm}$. The operating principle of this dynamometer is based on the fundamental laws of electromagnetism (Faraday-Lenz law) and the mechanical properties of elasticity of a spring. The values obtained of the surface tension with our device are in good agreement with the results expected found in the bibliography
\end{abstract}

Keywords: Electromagnetic dynamometer, Wilhelmy plate method, accuracy, surface tension.

\section{INTRODUCTION}

The surface tension of liquids is an important physical parameter, theoretically as well as practically. It is, by definition, a contractive tendency of the surface of a liquid that allows it to resist an external force; in other words, it is the free energy per unit of surface associated to the formation of the interface considered $(\mathrm{J} / \mathrm{m})$. It can also be expressed as a force per unit length $(\mathrm{N} / \mathrm{m})$ [1]. The methods for measuring the surface tension are numerous: methods using drops [2], methods based on the energy required to deform a fluid interface [3-4] and methods based on the study of the light scattered by the surface waves[5-6]. The choice of the appropriate method depends on the nature of the interface (between pure phases or between solutions), the speed of voltage change over time, the desired accuracy, ease of operation and the apparatus cost.

In this paper, we presented our approach to design and implement an electromagnetic dynamometer for measuring the surface tension by Wilhelmy plate method, we have chosen this technique for convenience reasons.

The existing force sensors are generally electrodynamics, piezoelectric or using strain gauge [7-8-9]. The operating principle of the sensor that we propose is based on the fundamental laws of electromagnetism and the mechanical properties of elasticity of a spring.

\section{ELECTROMAGNETIC DYNAMOMETER}

\subsection{Description}

Our goal is to design and produce an electromagnetic dynamometer with an important extensive measurement and accuracy for measuring the surface tension of liquids. The operating principle of the proposed sensor is based on the fundamental laws of electromagnetism, which justifies its name "Electromagnetic force sensor."

This sensor consists of two flat circular coils of a diameter of $2 \mathrm{~cm}$ and 30 coil turns made by a copper conductor wire of a section of $0,06 \mathrm{~mm}$, placed in parallel. One of the flat coils (Fixed Coil) is fixed on an insulating horizontal support and the other flat coil (Moving Coil) is wound on an insulating cylinder of $2 \mathrm{~cm}$ in diameter, the lower end passes through the free surface formed by the coil fixed, and the upper end is connected to a spring which is itself attached to a fixed support. At the lower end of the cylinder that acts as a guide, we set a hook for hanging masses.

The entire system formed (fixed flat coil, guide roller, spring and moving flat coil) is aligned on the same vertical axis (Fig-1).

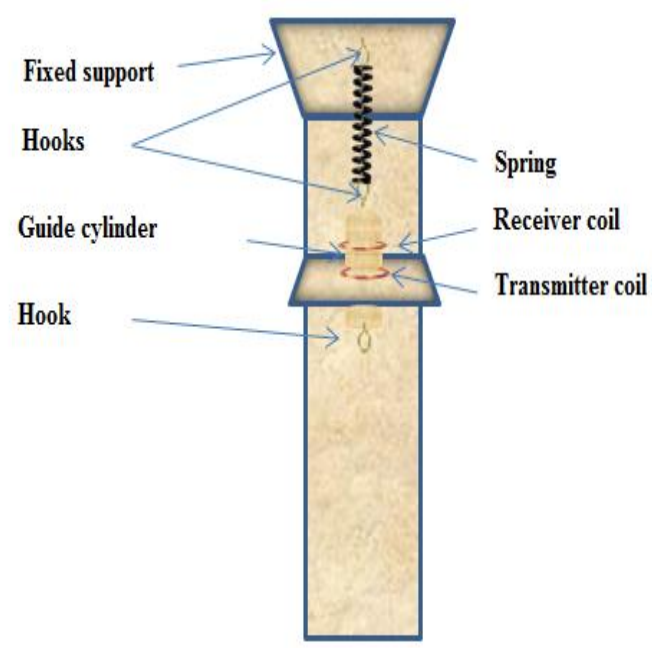

Fig -1: Electromagnetic force sensor 
The cylinder is movable vertically upwards or downwards virtually without friction, when we exert a force on its lower end, which has the effect of extending or compressing the spring, this action bring closer or away the guide cylinder (moving coil) from the fixed coil.

The fixed coil is supplied by an low frequency generator of a frequency $\mathrm{fO}=16 \mathrm{KHz}$ whose phase conditions and amplification are satisfactory, and therefore it is traversed by a sinusoidal current which creates a sinusoidal magnetic flux density along its axis, the latter creates through the moving coil a variable flow $\Phi$ and induced sinusoidal electromotive force measurable, the maximum value of the EMF induced depends on the distance $\mathrm{x}$ between the two coils, the flux $\Phi$ is proportional to the magnetic induction $\mathrm{B}$ that changes as a function of $\mathrm{x}$ are given by the following relation:

$$
B(x)=\frac{\mu_{0} I R^{2}}{2 \sqrt{\left(R^{2}+x^{2}\right)^{3}}}
$$

With I: Maximum amplitude of the current flowing through the coil, $\mathrm{R}$ : coil radius and $\mathrm{x}$ is the distance between the two coils.

The magnetic field created by the transmitter coil is at a maximum at the center of the coil $(x=0)$ :
The second flat moving coil is the receiver coil; it acts as an inductive sensor which converts a magnetic field passing therethrough to a voltage. This receiver coil at a distance $x$ from the fixed flat coil will receive an electromotive force whose expression is given by the Lenz-Faraday law e = $\mathrm{d} \Phi / \mathrm{dt}$. The magnetic flux $\Phi$ through the receiver coil is proportional to the magnetic induction $\mathrm{B}$ whose variations in terms of $\mathrm{x}$ are given by the relation (1), and therefore the induced electromotive force will have similar variations in function of $x$ in a given frequency. The maximum amplitude of this induced voltage will be greater as the frequency is higher. Thus, we realized an electromagnetic displacement sensor, at each position $\mathrm{x}$ of the receiver coil corresponds a determined induced voltage, this voltage takes its maximum value when the two coils are juxtaposed and decreases as the receiver coil moves away from the transmitter coil. The use of the spring, which acts as a force-displacement converter, has allowed us to use the sensor as a force sensor.

When a mass suspended on the hook on the bottom of the cylinder, the latter moves down by extending the spring, and the distance $\mathrm{x}$ between the two coils is reduced and as a result the voltage induced across the receiver moving coil increases. The induced voltage is sinusoidal and its amplitude is low, so it has been necessary to introduce circuits for amplification, rectification and filtering to make this voltage usable, the corresponding sensor output signal conditioning circuit is as follows:

$$
B_{0}=\frac{\mu_{0} I}{2 R}
$$

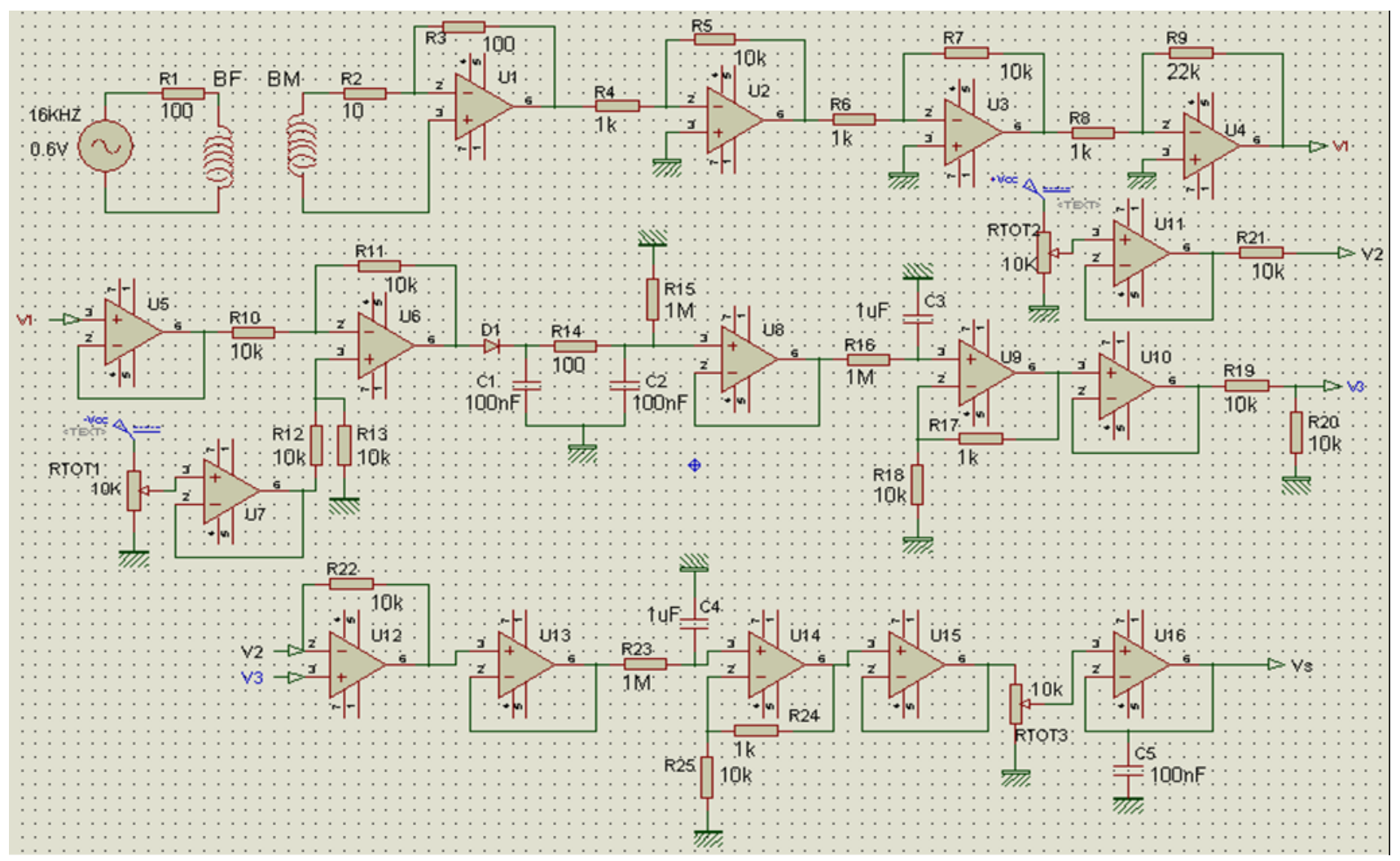

Fig -2: Conditioning circuit 
Amplifiers used are LM324 which are power supplied from a $\pm 15 \mathrm{~V}$ symmetrical stabilized source.

\subsection{Characteristics of the Electromagnetic}

\section{Dynamometer}

\subsubsection{Sensor Drift}

When we turn the sensor on, the output voltage decreases exponentially and after 10 to 20 minutes of operation, this voltage stabilizes at a characteristic constant of the experimental device.

\subsubsection{Sensitivity}

The sensitivity of the sensor depends on the spring constant of the spring used and conditioning circuit (particularly the gain of the amplifier stages), we achieved a sensitivity of $3 \mathrm{mg} / \mathrm{mV}$ at the beginning (before suspending masses). However, the electromagnetic unit consisting of transmitter and receiver coil may be modified to increase the sensor sensitivity. In general, inductive sensors were first used for historical reasons, but are still interesting because of their accuracy and robustness. In addition, the coils are cheap and easy to produce industrially, at least within reasonable dimensions. The induction of a coil is directly related to its number of turns, its diameter and thus its size; the small coils generally have a lower sensitivity. However, advanced techniques now allow the production of coils of small size with high sensitivity, with complex shapes or a larger number of turns. The frequency domain for an inductive sensor depends strongly of its impedance.

\subsubsection{Measuring Range}

From $0 \mathrm{~g}$ to $1.1 \mathrm{~g}$, it's related to the mechanical properties of the spring. The sensor is designed to work in a range of 0 to $1.1 \mathrm{~g}$.

\subsubsection{Accuracy}

The sensor accuracy depends on the specific elements of the experimental device (coils, cylinder, friction, distance between coils, spring, and the signal conditioning circuit), and on the quality of the measuring instrument used. In our case we used a digital multimeter whose accuracy is $0.1 \mathrm{mV}$. The voltages delivered by the sensor are measured with an error of $0.5 \mathrm{mV}$, and the accuracy of the measured masses is estimated to $\Delta \mathrm{m}=0.3 \mathrm{mg}$ at the origin. So we can say that all measure masses between 0 and $1.1 \mathrm{~g}, \Delta \mathrm{m}$ is equal or less than $\Delta \mathrm{m}=0.3 \mathrm{mg}$. This is related to the sensor sensitivity which is variable and depends on the distance between coils, this sensitivity changes from $3 \mathrm{mg} / \mathrm{mV}$ to $2 \mathrm{mg} / \mathrm{mV}$, so 0.2 $\mathrm{mg} \leq \Delta \mathrm{m} \leq 0.3 \mathrm{mg}$.

\subsubsection{Hysteresis}

We have made measurement on the sensor by hooking increasingly masses of $0 \mathrm{~g}$ to $1.1 \mathrm{~g}$ per $100 \mathrm{mg}$ in steps of $100 \mathrm{mg}$, and then we note the output voltage values by removing masses in steps of $100 \mathrm{mg}$. The results are perfectly reversible and there was no hysteresis cycle due to the mechanical properties of the spring which acts as a force-displacement converter. We were limited to a maximum weight of $1.1 \mathrm{~g}$, and beyond, there is a small deformation appearing. The choice of a good spring (perfectly elastic) is important. The spring constant of the spring used is $\mathrm{k}=2 \mathrm{mN} / \mathrm{mm}$.

\subsection{Sensor Response from $0 \mathrm{~g}$ to $1.1 \mathrm{~g}: \mathrm{V}=\mathrm{f}(\mathrm{F})$}

The characteristic curve of the sensor shown in Chart-1 is obtained by hooking high-precision masses from $0 \mathrm{~g}$ to $1.1 \mathrm{~g}$ in steps of $100 \mathrm{mg}$ (Table-1), and we note the voltage values corresponding to each mass. The curve response is not linear; it is rather parabolic in relation with the sensor sensitivity as a function of the distance between coils.

Table -1: Sensor calibration

\begin{tabular}{|l|l|l|l|l|l|l|l|l|l|l|l|l|}
\hline $\mathrm{M}(\mathrm{mg})$ & 0 & 100 & 200 & 300 & 400 & 500 & 600 & 700 & 800 & 900 & 1000 & 1100 \\
\hline $\mathrm{V}(\mathrm{mV})$ & 232,8 & 263,6 & 296,8 & 332,3 & 370,8 & 412 & 456,2 & 504,2 & 555,6 & 611,2 & 671,3 & 735,6 \\
\hline $\mathrm{F}(\mathrm{mN})$ & 0 & 981 & 1962 & 2943 & 3924 & 4905 & 5886 & 6867 & 7848 & 8829 & 9810 & 10791 \\
\hline
\end{tabular}

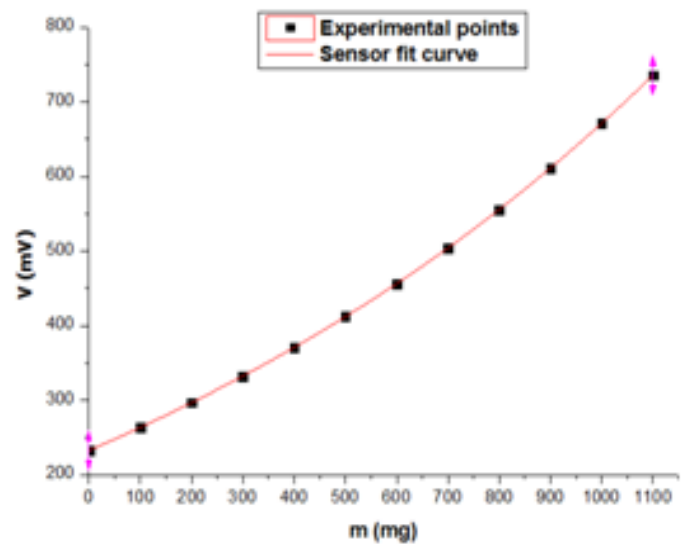

Chart -1: Sensor response from $0 \mathrm{~g}$ to $1.1 \mathrm{~g}$ : $\mathrm{V}=\mathrm{f}(\mathrm{m})$

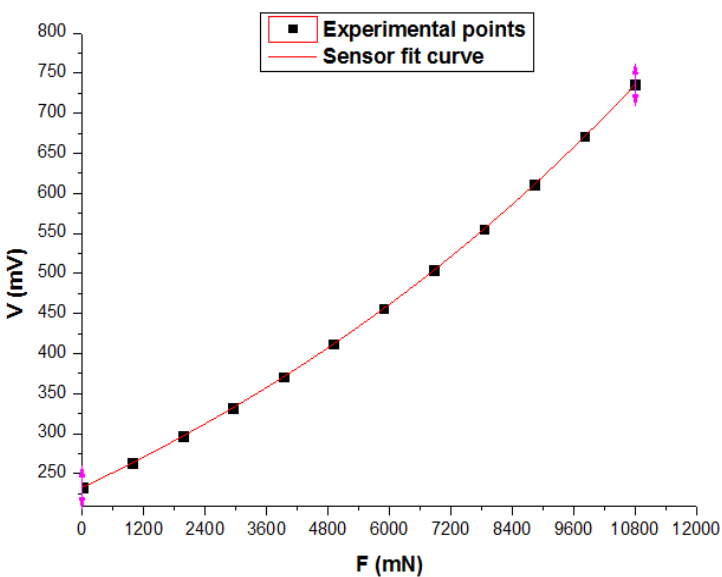

Chart -2: Sensor response from $0 \mathrm{~g}$ to $1.1 \mathrm{~g}$ : $\mathrm{V}=\mathrm{f}(\mathrm{F})$ 
We used a polynomial fit of order 5 which is characterized by a standard deviation commensurate with the experimental sensor accuracy. The polynomial fit of the mass as a function of the voltage $(m=f(V))$ shown below will be most useful for determining the mass of any unknown by knowing its corresponding voltage delivered by the sensor. The corresponding polynomial adjustment is given by:

$$
m=\sum_{i=0}^{5} a_{i} V^{i}
$$

With $\mathrm{v}$ in $\mathrm{mV}$, and $\mathrm{m}$ in $\mathrm{mg}$ and $\mathrm{F}$ in $\mathrm{mN}$

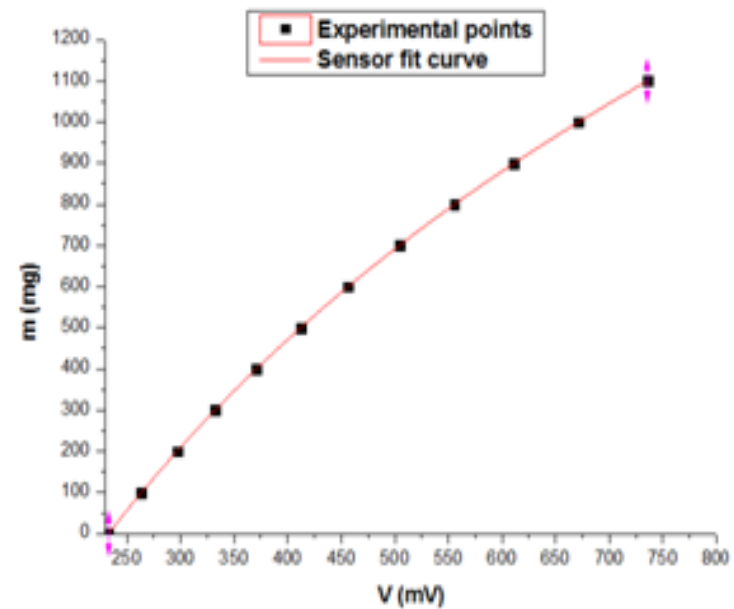

Chart -3: Sensor response from $0 \mathrm{~g}$ à $1.1 \mathrm{~g}: \mathrm{m}=\mathrm{f}(\mathrm{V})$

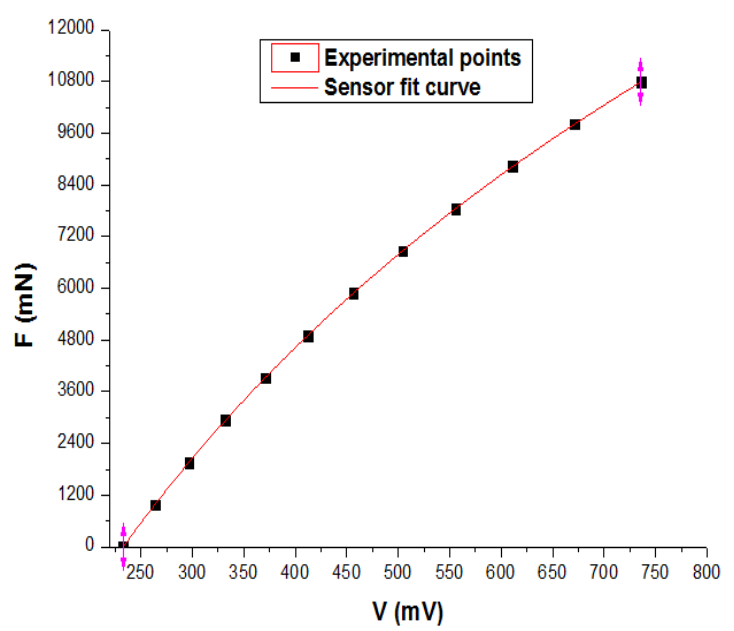

Chart -4: Sensor response from $0 \mathrm{~g}$ à $1,1 \mathrm{~g}: \mathrm{F}=\mathrm{f}(\mathrm{V})$

The polynomial adjustment of the mass as a function of the voltage corresponding to the experimental accuracy of our sensor is as follows:

$$
\mathrm{m}(\mathrm{mg})=\mathrm{A}+\mathrm{B}_{1} \mathrm{~V}+\mathrm{B}_{2} \mathrm{~V}^{2}+\mathrm{B}_{3} \mathrm{~V}^{3}+\mathrm{B}_{4} \mathrm{~V}^{4}+\mathrm{B}_{5} \mathrm{~V}^{5}
$$

With:

$\mathrm{A}=-1103.37738 ; \mathrm{B}_{1}=6.65807$

$\mathrm{B}_{2}=-0.01113 \quad ; \mathrm{B}_{3}=1.50209 * 10^{(-5)}$

$\mathrm{B}_{4}=-1.22139 * 10^{(-8)} ; \mathrm{B}_{5}=4.29683 * 10^{(-12)}$ $\mathrm{r}^{2}=1 \quad$ and $\sigma=0.24913$

$\mathrm{Bi}$ : Coefficients of the characteristic polynomial.

r2 : Correlation coefficient

$\sigma:$ Residual sum of squares

\section{Surface Tension of Systems $x\left(\mathrm{C}_{2} \mathrm{H}_{6} \mathrm{O}\right),(1-x) \mathrm{H}_{2} \mathrm{O}$}

\subsection{Preparation of Water-Ethanol Mixtures}

$x$ represents the mole fraction of the absolute ethanol.

The mixtures were prepared by using absolute ethanol and distilled water.

To analyze in good conditions the influence of the mole fraction on the surface tension, we systematically prepared 26 systems whose mole fraction $\mathrm{x}$ is ranged from 0 to 1 with intervals:

$\begin{cases}\Delta x=0,025 & \text { from } 0 \text { to } 0,2 \\ \Delta x=0,05 & \text { from } 0,2 \text { to } 0,8 \\ \Delta x=0,025 & \text { from } 0,8 \text { to } 1\end{cases}$

By mixing a mass $\mathrm{m}_{1}$ of a liquid whose molar mass is $\mathbf{M}_{1}$, and a mass $m_{2}$ of a liquid whose molar mass is $M_{2}$, we get a system of mass $\mathrm{m}$ whose weight concentrations are related to the mole fractions by the following relations:

$$
\begin{aligned}
& c_{1}=\frac{m_{1}}{m_{1}+m_{2}}=\frac{1}{1+k\left(\frac{1}{x 1}-1\right)} \\
& c_{2}=\frac{m_{2}}{m_{1}+m_{2}}=\frac{1}{1+k\left(\frac{1}{x 2}-1\right)}
\end{aligned}
$$

The molar masses of ethanol $\left(\mathrm{C}_{2} \mathrm{H}_{6} \mathrm{O}\right)$ and water $\left(\mathrm{H}_{2} \mathrm{O}\right)$ are respectively:

$$
\mathrm{M} 1=46 \mathrm{~g} \text { and } \mathrm{M} 2=18 \mathrm{~g}
$$

And:

$$
K=\frac{M_{2}}{M_{1}}=0.39130 .
$$

We calculated the weight concentration $c$ of ethanol $(c=c 1)$ for each mole fraction, and the mass $\mathrm{m} 1$ corresponding to get a mixture of standard mass $(\mathrm{m}=100 \mathrm{~g})$. The weights were made by using Pionner precision balance sensitive to $0,0001 \mathrm{~g}$. 


\subsection{Surface Tension Measurements by Wilhelmy}

\section{Plate Method}

Although the Wilhelmy plate method for measuring surface tension of liquids is not new, and it has been the subject of similar work for a long time [10-11], we believe it can be useful, for experimenters that the measures interest, to describe an instrument of very simple construction, based on a new generation of force sensors.

This tearing method is to measure the force required to pull a solid body immersed on a liquid. The principle of this method is generally attributed to Lecompe du Nouy, well before the idea was less exploitable by Sondhaufs and Timberg, the solid body used by these researchers was a platinum ring. Since then, various authors have advocated symmetrical solid relative to an axis of various shapes: sphere vertical cylinder, ring, cone...[12].

The experimental device we provide for measurements of surface tension of liquids is constituted by an electromagnetic force sensor, a thin rectangular plate, a laboratory jack and a Pyrex beaker to put the test liquid (Fig.3).

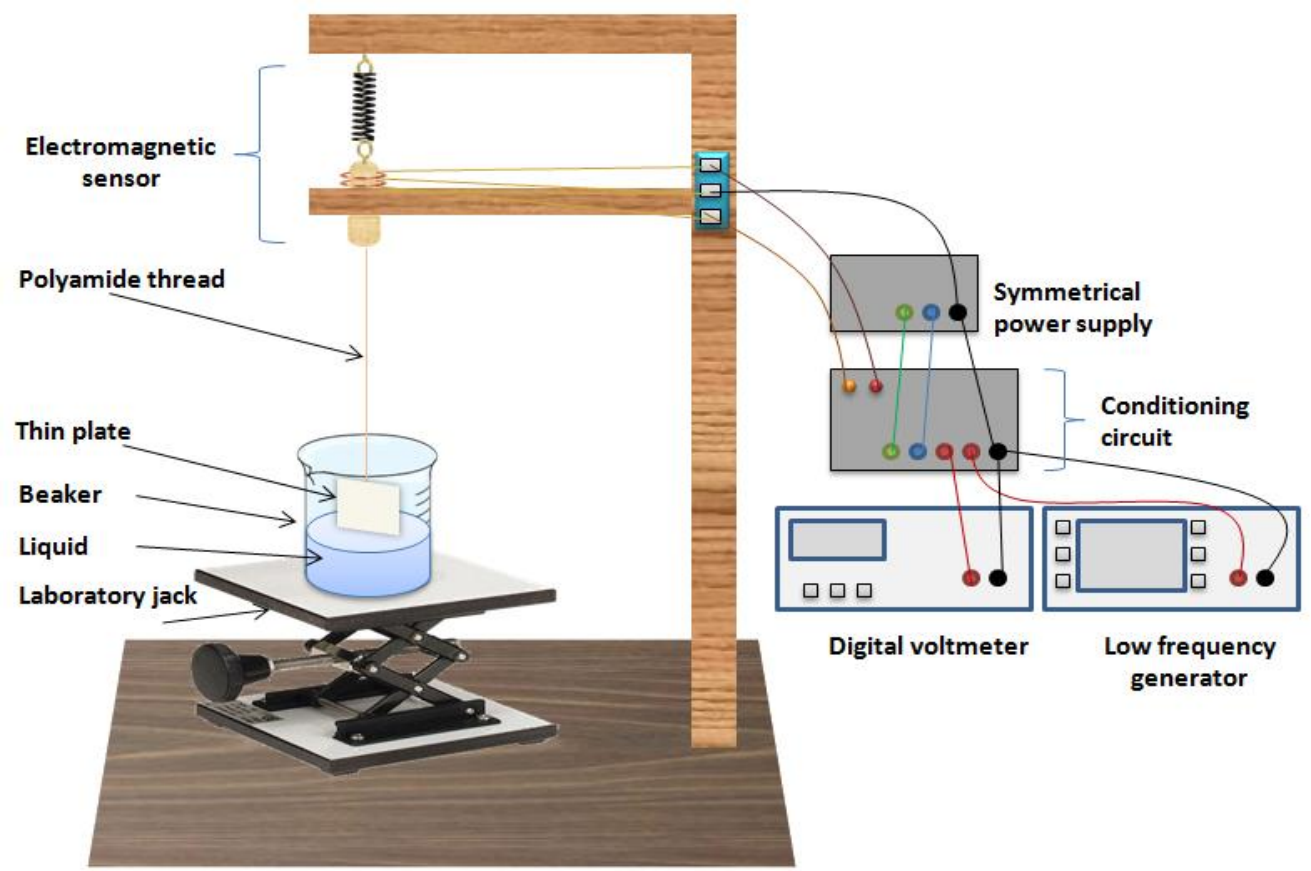

Fig -3: Electromagnetic dynamometer

The test liquid is contained in the beaker which is placed on the top of the laboratory jack, the thin plate is suspended on the sensor by a polyamide thread, and we make the contact between the base of the plate and the liquid by means of the laboratory jack. Then we send down the adjustable laboratory jack progressively with a very slow speed until the thin plate tends to separate from the liquid by forming a very thin film, the balance being consistently maintained.

The electromagnetic dynamometer allows us to measure the force on the edge of the tear and to deduce by a simple calculation the surface tension of the studied liquid using this equation:

$$
\mathrm{Fa}=\text { ma. } \mathrm{g}=2 \sigma(\mathrm{L}+\mathrm{e})
$$

$2(\mathrm{~L}+\mathrm{e})$ is the perimeter of the contour of the plate, $\mathrm{g}=9,82$ $\mathrm{m} / \mathrm{s} 2$ the gravity and $\mathrm{Fa}$ the breakout force of the plate at the limit of its separation from the liquid surface, this force is expressed in $\mathrm{mN}$, The surface tension in $\mathrm{mN} / \mathrm{m}$ or in dynes/cm .

\subsection{Results for the Water-Ethanol Systems at $\mathrm{T}=25.8^{\circ} \mathrm{C}$}

The calculation of the surface tension of each solution is obtained by using the equation (7).

The results for the water-ethanol systems are grouped in the following table:

Table -2: Summary of results for the water-ethanol systems

\begin{tabular}{|l|l|l|l|l|l|l|l|l|}
\hline $\mathrm{x}$ & 0 & 0,025 & 0,05 & 0,075 & 0,1 & 0,125 & 0,15 & 0,175 \\
\hline $\mathrm{V}(\mathrm{mV})$ & 352,6 & 296,2 & 291,8 & 285,8 & 281 & 278,7 & 277,8 & 277,3 \\
\hline $\mathrm{ma}(\mathrm{g})$ & 0,3536 & 0,1984 & 0,1855 & 0,1677 & 0,1534 & 0,1464 & 0,1437 & 0,1422 \\
\hline $\mathrm{Fa}(\mathrm{mN})$ & 3,469 & 1,946 & 1,820 & 1,646 & 1,505 & 1,436 & 1,410 & 1,395 \\
\hline$\sigma($ dynes/cm & 71,67 & 40,21 & 37,60 & 34,00 & 31,08 & 29,68 & 29,13 & 28,82 \\
\hline
\end{tabular}




\begin{tabular}{|l|l|l|l|l|l|l|l|l|}
\hline 0,2 & 0,25 & 0,3 & 0,35 & 0,4 & 0,45 & 0,5 & 0,55 & 0,6 \\
\hline 276,2 & 275 & 273,7 & 272,8 & 272,4 & 271,8 & 271 & 270,3 & 270 \\
\hline 0,1388 & 0,1352 & 0,1312 & 0,1285 & 0,1272 & 0,1254 & 0,1229 & 0,1208 & 0,1198 \\
\hline 1,362 & 1,326 & 1,287 & 1,260 & 1,248 & 1,230 & 1,206 & 1,185 & 1,176 \\
\hline 28,14 & 27,40 & 26,59 & 26,03 & 25,79 & 25,41 & 24,91 & 24,48 & 24,29 \\
\hline
\end{tabular}

\begin{tabular}{|l|l|l|l|l|l|l|l|l|}
\hline 0,65 & 0,7 & 0,75 & 0,8 & 0,825 & 0,85 & 0,875 & 0,925 & 1 \\
\hline 269,4 & 268,9 & 268,6 & 268,3 & 268 & 267,8 & 267,7 & 267,3 & 265,8 \\
\hline 0,1180 & 0,1164 & 0,1155 & 0,1146 & 0,1137 & 0,1130 & 0,1128 & 0,1115 & 0,1068 \\
\hline 1,157 & 1,142 & 1,133 & 1,124 & 1,115 & 1,109 & 1,106 & 1,094 & 1,048 \\
\hline 23,91 & 23,60 & 23,41 & 23,22 & 23,04 & 22,91 & 22,85 & 22,60 & 21,65 \\
\hline
\end{tabular}

The change in the surface tension as a function of the mole fraction $\mathrm{x}$ is shown in the following figure:

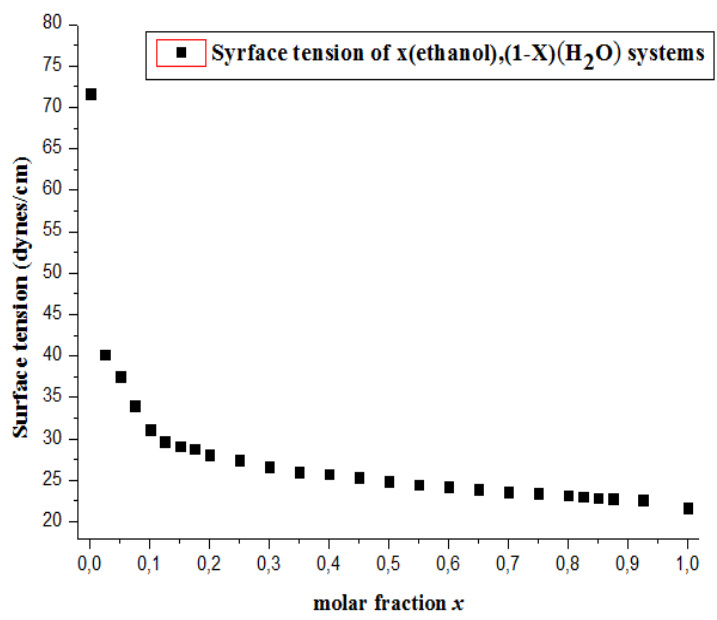

Chart -4: Surface tension as a function of the mole fraction $x$

The water-ethanol systems according to the mole fraction $\mathrm{x}$ show an important decrease in the surface tension for the solutions rich in water, followed by a small variations in terms of the mole fraction.

We note a great decrease in the value of the surface tension of water after adding just an amount of $2,5 \%$ of ethanol which shows that the water is too sensitive to impurities.

\subsection{Results Obtained for Some Absolute Products at $\mathrm{T}=24.3^{\circ} \mathrm{C}$}

Table -3: Summary of results for the absolute products $\left(\mathrm{T}=24.3^{\circ} \mathrm{C}\right)$

\begin{tabular}{|l|l|l|l|l|}
\hline produits & eau distillée & acide acétique absolu & Méthanol absolu & Ethanol absolu \\
\hline $\mathrm{V}(\mathrm{mV})$ & 357,7 & 279 & 271,2 & 270,2 \\
\hline $\mathrm{ma}(\mathrm{g})$ & 0,3585 & 0,1380 & 0,1141 & 0,1110 \\
\hline $\mathrm{Fa}(\mathrm{mN})$ & 3,516 & 1,354 & 1,119 & 1,089 \\
\hline$\sigma($ dynes$/ \mathrm{cm})$ & 71,91 & 27,69 & 22,89 & 22,27 \\
\hline
\end{tabular}

Results for these absolute products are in good agreement with the results expected found in the bibliography.

\subsection{Sensitivity and Accuracy of the Experimental Device}

According to the relation between the surface tension $\sigma$ and the breakout force $\mathrm{Fa}$, we deduce that the device is more sensitive than the width of the plate is great, but we cannot increase this width because of the weight limit that cannot be exceeded. Besides this, the horizontality problems of the thin plate will arise and distort the measurements. Knowing that $\Delta \mathrm{m}=0.3 \mathrm{mg}$, which corresponds to $\Delta \mathrm{F}=0.3 \cdot 10^{-2} \mathrm{mN}$ and $2(\mathrm{~L}+\mathrm{e})=4.84 \mathrm{~cm}$, then the minimum change in surface tension that can be measured is $\sigma=0.06$ dynes $/ \mathrm{cm}$, variations below 0.06 dynes/cm cannot be detected.

The measurement accuracy depends on the sensitivity of the force sensor and the thin plate width and thickness that we must know with great precision. 


\section{CONCLUSIONS}

We realized a new electromagnetic dynamometer which allows studying the surface tension variations of liquids and liquid mixtures as a function of the mole fraction $\mathrm{x}$.

The results obtained with this dynamometer [13] for absolute products are in good agreement with the bibliographic results, and the surface tension values experimentally obtained for water-ethanol mixtures as a function of the mole fraction show an important decrease in the surface tension for the solutions rich in water, followed by small variations in terms of the mole fraction $\mathrm{x}$.

We cannot overlook the errors caused by evaporation, during measurement or during the preparation of mixtures, especially for Alcoholic solutions [14]. But, despite the difficulties we have prepared good mixtures and have had good results by following the instructions.

Other improvements can be imported to our device to increase sensitivity and measuring range to make it more innovative and more efficient.

\section{REFERENCES}

[1]. P. PAINMANAKUL, thèse (Toulouse 2005)

[2]. C.Yao-Yuan, L. Shi-Yow, Surface tension measurement of glass melts using sessile or pendant drop methods, Journal of the Taiwan Institute of Chemical Engineers 42 (2011) 922-928

[3]. B. Jedidi Yaïchi, K. Debbabi, R. Naejus, C. Damas, R. Coudert, A. Baklouti, évaluation

des propriétés tensioactives d'une série de f-alkyl $\alpha$ bromoesters oligoéthoxylés monoalkylés, Journal de la Société Chimique de Tunisie, 2009, 11, 109-117

[4]. K. Sakai, Y. Yamamoto, Electric field tweezers for characterization of liquid surface, Appl. Phys. Lett. 89 (2006) 211911

[5]. C. Sohl, K. Miyano, J. Ketterson, Novel technique for dynamic surface tension and viscosity measurements at liquid-gas interfaces, Rev. Sci. Instrum. 49 (10) (1978) 1464-1469

[6]. K. Sakai, D. Mizuno, K. Takagi, Measurement of liquid surface properties by laser-induced surface deformation spectroscopy, Phys. Rev. E 64 (2001) 046302.

[7]. DA SILVA et al, A Strain Gauge Tactile Sensor for Finger-Mounted Applications, VOL. 51, NO. 1, FEBRUARY-2002

[8]. J.-L. Le Goer, J. Avril, Capteurs à jauge extensométrique, Techniques de l'ingénieur, pp. 01, 2000

[9]. O. Kursua, A. Kruusingb, M. Pudasb, T. Rahkonen, Piezoelectric bimorph charge mode force sensor Timo Rahkonena, article science direct, 2009

[10]. H. LEMONDE, Tensiomètre à lame flexible pour la mesure des tensions superficielles, Journal de physique et le radium, décembre 1938

[11]. N Wu, J Dai, FJ Micale - Journal of colloid and interface science, 1999, Dynamic surface tension measurement with a dynamic Wilhelmy plate technique
[12]. J. BRIANT, Phénomènes d'interface, agents de surface: principes et modes d'action. 1989, p: 60

[13]. WO2014011020 A1 Tensiomètre, PCT/MA2012/000035 Abdelrhani Nakheli\&Seddik

Bri.

[14]. J. Hommelen, Sur les Erreurs Causées par L'Évaporation dans les Mesures de Tension Superficielle (1 SEP 2010) 